\title{
Awareness and Use of Information Technology through a Theoretical and Constructive Observation of Academic Libraries
}

\section{Abstract:}

\section{Dr. Rajeshkumar M.Gamit}

In today's the changes that are taking place in the world, the information technology revolution is making the biggest impact of the world. In this 21 st Century era of information technology, educational libraries provide a new technology-based role to meet user demand through information technology services. Information technology is thanks to the services that are provided to all types of users for new methods in new environments through new services. With the use of information technology, the information technology revolution is making the biggest impact in all sectors of the world, today including education, social, economic, political, tourism and health etc. The use of information technology in academic libraries is very useful to meet the increasing demand of users. With the advancement of information technology, researchers, academics, librarians and policy makers have begun to increase the use of information technology in the education system. Today, the world is rapidly moving towards a global village to make educational library fields technology-free. Which are today goes beyond the leverage of information technology.

Key Words: IT, Academic Libraries, Environment, Researchers, Librarians, Policy

$$
\text { makers, World, }
$$

\section{Introduction:}

Information Technology has come to occupy the centre stage of development, with the approach of $21^{\text {st }}$ century. Some of the development started centuries ago, and their roots can be traced back to ancient civilizations. Information technology is social, 
economic, political need and technological innovation factors. It is becoming increasingly the key to national economic development and well-being, certainly to affect virtually every industry and service through significant qualitative and quantitative improvements in providing information, in designing products and services, in tackling and responding to a variety of demands and in supporting decision making.

Information Technology involves use of computers and information systems for storing, managing and accessing useful information in an optimized and organized way. Storage of large volume of data, effective data management, maintenance of data management, maintenance of data consistency and integrity and quick and ready access of data are some of the major features of IT. The IT revolution has embraced the academic, public, industries system. A massive and rapid computerization process throughout the educational system has made IT an integral part of the library management scene in many countries. Earlier computers belonged only to institutions and large organizations. Now the personal computers have placed computing power in the hand of numerous individuals. After the invention of the microprocessor, high-density storage devices, video tape recorders, compact disc, optical cables, satellite telecommunications and other information and communication technologies.

The incorporation of IT into the day-to-day activity of university libraries has a strong impact on virtually every aspect of their management process. Computerization of data processing and data mobilization can support library staff in their daily activities; user e-resources improve effectiveness, efficiency and assist in attainment of educational goals. This can assist library professional in managing more informed decisions especially those involving several variables and more complex relationships among these variables. Thus it can contribute to services renewal; excellence enhanced professionalism and strengthened librarianship.

\section{Concept of Information Technology:}

The word 'Information Technology' is a combination of two words. One is 'Information' and the other is 'Technology' Information means knowledge can be a bit or a Para or a page. Technology refers to the use of computer and communications. It 
means the application of computer and communication technologies for gathering, processing, storage, retrieval and dissemination of information.

UNESCO defined IT as "The scientific, technological and engineering discipline and the managerial techniques used in information handling and processing; their application: computers and their interaction with men and machines and associated social, economic and cultural matters". (Enser, 1988). ${ }^{1}$

ALA Glossary defines IT as "the application of the computers and other technologies to the acquisition, organization, storage, retrieval and dissemination of information". (Patil, 1954). ${ }^{5}$

According to Rayudh, ${ }^{7}$ IT can be defined form the Library and Information Science point of view as "application of various technologies for the acquisition, processing, storage and dissemination of vocal, pictorial, textual and numerical information by a microelectronics based combination of computing and telecommunication"

Information Technology and microelectronic are largely over leaping, According to Resnikoff, ${ }^{8}$ Information technology encloses such different things as "book print, reprography, the telephone network, broadcasting, the typewriter and the computer" Bhatt (2012) revealed that most of Medical College Libraries are having a sound ICT based Infrastructure in the state of Gujarat and providing hassle free access to their patrons. Bhatt (2014) discussed that the law faculty members use electronic resources at maximum level in compare to print resources due to promotion of online legal resources. Law librarians' need to focus on user education programmes to promote the use of eresources.

IT can be regarded as a major economic factor in the development post-industrial society; the production and sale of IT goods has revitalized some section of economy and to a small extent, replaced some of the losses, brought about by the decline in manufacturing. Since it can contribute to economic growth and development by reducing 
costs, improving and or extending services, strengthening, competitive advantages and soon.

\section{Statement of Problem of the Study:}

Most of the except few academic libraries, have not yet started utilizing or application of IT even in the house keeping functions of the library due to inadequate finance and man power. It is observed that UGC and State Government have been extending the financial help for the automation of the academic libraries in India. There are different types of software available for library housekeeping functions. All the librarians must get ready by keeping abreast of latest information technology in order to face the new challenge in information field of academic Libraries. Technology will undoubtedly pay a growing role in the library of the future. Nevertheless, Librarians will continue to make their decisions in the context of their overall needs and resources. The problem in application of information technology in library field or for its slow progress is many out of which the few important ones are:

1. Installation of computer in libraries is still considered as costly affair.

2. It lacks in sufficient trained specialized manpower to plan and operate automation in libraries.

3. Non-availability of enough information technologies in Gujarat so as to facilitate automation in libraries and much responsibility lies on the shoulders of trained and well qualified library staff who could take initiative to introduce them.

Information Technology will continue to be the only a tool for the librarians to achieve the objectives and the answers to all problems.

\section{Impact on Academic Libraries in Information Technology:}

The single force that has brought revolutionary changes in functioning of academic libraries is information technology. Academic Libraries are using the IT to increase the efficiency and effectiveness of their operations and services. IT has virtually immense potential for a variety of applications in libraries. IT helps libraries in crating 
databases of their collections and making them available for easy access to users inside as well as outside through networks.

In an digital library, once databases are developed in the computer, many services like bibliographic service, indexing services, CAS, SDI etc. will be automatically generated from them the users can have direct access to them. IT offers a variety of computers based information products and services including access to external databases, CD-ROM etc. Net working has enabled libraries to share their resources more effectively, especially in the present days of increasing documents princes and decreasing library budgets.

IT enables libraries to provide most efficient and specialized information services. It has been fairly established that efficient information support and effective communication in an organization are closely associated with high performance, productivity and innovation. A study ${ }^{\mathbf{1 0}}$ on how IT can affect the ability of individuals or organization has found that IT enhanced innovation significantly by augmenting individual/ group capabilities through motivation support, resources support and information support. Among the three, motivation support was found to be the strongest factors. A survey by Hayter and Heery on impact of IT on senior managers in academic libraries in UK showed that nearly $60 \%$ senior staff have computer of some description in their office. Computerized activities include writing preparing reports, sending and receiving e-mail, on-line information gathering and maintenance of personal diaries and databases.

Computer can be used in performing most of the repetitive works of library in a desired number of times speedily and economically without fatigue and wastage of time. A study conducted on the use of computer in libraries of higher education showed that the time taken in processing 500 books in a library manually as well as through computer was 1000 hours and 60 hours receptively. The point to be noted here is that time required for typing/ data entry was the same number if 40 hours for both the systems. These shows that a computerized system is about 50 times cost-effective compared to noncomputerized one for the university libraries. Most of the operations within library are 
inter-related, interdependent and mutilate supportive for the overall mission of the library. Use of IT applications to interface and integrated each function with the other saves lot of staff time as the same data need not be entered at every stage. Data once entered in machine-readable form can be used repeatedly in different operations for various purposes. The use of IT with its immense capabilities of acquiring, storing, processing, retrieving and disseminating information with high speed and accuracy has made a tremendous impact on the overall functioning of libraries in the country.

The E-resources who are library clients-actual and potential should be made were of the application on information technology in library services. The major concern must be of developing manpower trained in information technology, of educating the existing library staff and maintaining continuing education given the changing nature of the information technology.

The overall impact of information technology on Academic Libraries, is broadly subdivided into three major divisions, such as,

1. Technical Services

2. User Services

3. Library Organization Structure

\section{Technical Services:}

The technological developments, which seen to have had the widest impact to data on technical services in libraries, are the growth and development of bibliographic utilities and the more recent development of integrated automated local systems. Bibliographic utilities have prospered in large part because of the role they play in cataloguing, Automation, in the form of bibliographic utilities and MARK format, has revolutionized the practice of cataloguing. Today's librarians rely on MARC format to provide proper cataloguing services to their users.

OPACs (On-line Public Access Catalogue) can substantially reduce the cost of maintaining a catalogue. Many paper files can be eliminated and decentralization is possible because, staff can access the on-line files, wherever a terminal is located. If the 
OPAC is integrated with other technical service files in a full function automated system, work throughout the department can be streamlined and reorganized. The impact on staff responsibilities and assignments can be significant. Serials automation has proceeded more slowly than that of other technical services operations. The undertaking has been difficult, complex and frustrating. But after the quick proliferation of information technology, successful implementation of automated serials control, including check-in, claiming, binding control and routing of materials has become more feasible.

Collection development may be treated as part of public services or as part of technical services. It may be carried out within the acquisitions department or in a separate unit. Regardless of the organizational arrangements, libraries who select materials for the collection use a variety of bibliographic tools automation has made available many of these tools in machine readable format and offered new ways of monitoring collection development and management activities. Co-operative collection development and management have become increasingly important in libraries due to tight budgets, rising prices and the information explosion. Bibliographic utilities facilitate these efforts through shared holdings, information and automated interlibrary loan subsystems to speed resource sharing.

\section{User Services:}

OPACs, which provided speedy on-line access to the entire library's holding by means of computer terminals, are affecting library operations as powerfully as has the appearance of bibliographic utilities and automated regional networks. OPACs serving either a single institutions are now wide spread and continue to be implemented in libraries across the country. Now optical technologies make possible and affordable the mounting of CD-ROM public catalogues at standalone microcomputer stations an operational reality in virtually any library. Advances in library automation also made possible the rapid development of union lists of serials, arranging holding information for a number of libraries. Library networks made available a central agency that could assemble, merge, and maintain the bibliographic and holding information of other libraries. The development of technology had provided significant improvements in 
'resource sharing', especially in interlibrary loan operations. As in technical services, public services operation have experienced movement of the more routine functions to lower level of staff, as a result of library automation. The verification of bibliographic citations has often become routine and is handled as ready 'reference' searching by support staff. The new emphasis on access to sophisticated information sources has placed new demands on the librarians. Therefore librarian often expected to train and advise patrons in their use.

\section{Library Organizational Structure:}

A right type of planning is vital for the efficient working of a library. Planning of a library organizational structure requires a thorough understanding of need of the users, objectives and functions of a library or information center. The emergence of information technology provided greater impetus for information transfer at both inter and intraorganizational level. Organization of all types become involved with information technology and have implemented, information technology based systems. Information technology will decrease the human work and alters the existing organization structures.

\section{Objectives of the study:}

The objectives of information technology in library and information can be categorized into the following four groups.

1. Supporting technical functions associated with technical processing and circulation work.

2. Supporting information storage, retrieval and dissemination systems.

3. Supporting management information services for libraries, especially analyzing library statistics.

4. It can best be used in service and orientation courses for practicing librarians, continuing education programs for teachers of library and information science, correspondence studies and library extension services.

\section{Need and Importance in IT of Academic Libraries:}


There are a number of reasons why IT is becoming a subject of wide-ranging discussion and study. Each of their reasons is significant on its own, but by acting together, as they are adding urgency to the need to understand the technical and social issues involved.

There has been an explosive growth in the volume of information leading to emergence of information society. It has been estimated that one trillion pages of information were generated in USA alone in 1993. It is observed that USA produced only about $25 \%$ of total world's information output. Therefore the total output of the world crosses 4 trillion pages in one year which is growing at the rate of 6 to $11 \%$ per year over the past decade. As a result of knowledge explosion, consumers have been confronted with the problems of searching and retrieving the required information in right time. It has been estimated that on average professionals spend 5 to $15 \%$ of their time on reading but up to $50 \%$ of their time looking for information. (Katherine) ${ }^{2}$

The storage and maintenance of huge information on paper documents have become extremely costly, time consuming and labour intensive. Printing itself is one the costliest options now available for disseminating information. Information storage medium has been drastically changed over the years form storage, i.e. papyrus, clay tablets, leather, paper or plastic to huge information in text, audio, video form and speedy dissemination to the needy around the world. As observed by Martin Katherine(1994) one megabyte of the information on paper might cost on an average four dollars on diskette perhaps 1.7 dollars and on CD-ROM might average 0.0024 dollars or even less If IT is not going to be used, than the society becomes handicapped, because of socialeconomic development of a nation depends upon the availability of adequate infrastructure to access the modern information, which is an essential ingredient in day to day decision making process, necessary for some the following reasons.

1. Advantage like Speed, Accuracy and reliability in the process of information due to introduction of IT. This also helps information consumers in performing the search quicker and with precision. 
2. The vast published literature in keeping abreast of the know-how and the development of IT.

3. Due to escalation of prices of periodicals and books, no library can afford to acquire all the publications. This necessitates active resources sharing among libraries. This is really successful on through networking to participate in the network; computerization of libraries is a prerequisite. For this reasons also, the librarians are tending towards involvement in IT.

4. Literature in almost all the fields is increasing tremendously in multidimensional way. It is posing a major problem to have bibliographic control on the basis of manual operations. This is only possible through computer applications.

5. Information seeking behavior of consumers is also changing. To cater the needs of the consumer's storage capacities of information as well as retrieval techniques should be applied to supply them with modern information.

6. Making the right information available to the right consumer at the right time in the right place to take the right action is the aim of any modern library services.

The IT has brought the people of the globe nearer. Although application of the information technology is only about 25 years old it has revolutionized the information services. In libraries universal availability of bibliographies is difficult to achieve. But IT has made it possible in reality. Concerted efforts are on the adept the IT in all spheres of activities.

\section{Awareness and Use of Information Technology Components Tools in Academic}

\section{Libraries:}

The present study has been changing of major in Information Technology development in utilization of IT components tools are as under:

1. Computers

2. Hardware Requirements

3. CD-ROM 
4. Software Requirements

5. Internet

6. E-books

7. E-journals

8. E-Mail

9. Telnet

10. E-databases etc.

\section{Computers:}

In 1949, Bell laboratories developed the first transistor, into the era of solid state technology. Generation has been step by step technology in ABACUS has change of information technology in computer.

1. First Generation of Computer in research of computer in Vaccume Tube has Part of computer components following;

1. Mark-1 (1937-44) IBM (International Business Machine)

2. ENIAC (1946-46) (Electronic Numerical Integrator and Calculator)

3. EDVAC (1946-52) (Electronic Discrete Variable Automatic Computer)

4. EDSAC (1947-49) (Electronic Delay Storage Automatic Computer)

5. UNIVAC (1951) (UNIVersal Automatic Computer)

6. 701 Commercial Computers (1952) -Introduce IBM Corporation.

2. Second Generation Computer- Transistor-IBM1401 and ICL1901.

3. Third Generation Computer-Integrator Circuits-LSI chips.

4. Fourth Generation Computer- VLSI chips-INTEL-4004.

5. Fifth Generation Computer- Artificial Intelligence Computer.

\section{Hardware Requirements:}


Academic libraries are requirement of IT systems any PC preferably a good high-speed $733 \mathrm{Mz}$. Penyium-III processor, having $64 \mathrm{MB}$ of RAM of and 10.2 GB HDD. A good laser or inkjet printer and a modern (modulator/demodulator) are also necessary.

\section{CD-ROM (Compact Disc-Read Only Memory):}

CD-ROM was development in 1985. The growth of multimedia titles, games, entertainment and cheap availability of videodiscs, and the latest in software distribution through CDs made CD-ROM discs and drives more popular. The CD-ROM, as 12-cm and $1.2 \mathrm{~mm}$ thick disc can holding approximately 650-700 million characters (650-700 MB) equal to about 2,70,000 pages of plain text or about 60,000 suitably compressed images. The advantages of CD-ROM are its huge storage capacity, durability, transportability light weight, easy and fast access to and non-corruptibility of stored information, immunity to magnetic fields and amenability for parallel searching by multiple users in a Local Area Network (LAN) or wide Area Network (WAN) environment. CD-ROMs can be used to store abstract databases, full-length articles, images, audio and software.

The CD-ROM technology brought the beginning of most profound revolution for the library and information professionals. Most of the libraries prefer CD-ROM service due to enormous capacity of storing data quick retrieval of the same. Librarian started using CD-ROM networking in the early 1990' it resulted in a number of advantages to both the users and the librarians. Access form users point of view was much improved and searching for multiple discs become possible. Along with these advantages, some other problems began to crop in how the users find their information or data base they wanted from the network? How the users know the names of the databases in their subject areas? Appropriate networking software was thus necessary to make sure that databases could be made accessible to the users. Here the experience of the librarian with the retrieval skill and understanding of databases could be made accessible to the users. 
Here the experience of the librarian with the retrieval skill and understanding of database searching are being used.

\section{Software Requirements:}

Choice of software depends upon the purpose for which the computer would and the available services provide by the service provider. Communication software is commonly used in combination with a modern. Packages fall two categories, i.e. Terminal Packages and TCP/IP based package. Terminal packages are user for accessing most host/shell account systems and TCP/IP based package enable a computer becomes a host on the internet. Software like LIBSYS, SANJAY, and SOUL are widely by the University Libraries for automation of their house keeping operations. Selection of the right software is a very job for the librarian. Selection of right Internet service provider is very important. The university librarian should take utmost care to select the internet services provider. The library administration should consider the following points in choosing a service provider.

\section{Internet:}

The internet, which is now well development, provides unprecedented opportunities for storage, retrieval and dissemination of information. Internet provides access to the most diversified source of information hosted by individuals and various organizations worldwide on a vast network of servers. The emergence of Internet offers very high bandwidth, which will widen the scope for information processing and dissemination as never before. A user will be able to cross-correlate information in multiple ways and that too from selected sources in this new networking environment.

Internet is the most talked about subject in library and information science field. If we take any journal of library science we will surely fine at least one article on Internet. 
Internet is transformation the library systems and the way in which we view information resources. The idea of library as a place is being questioned now. Librarians are forced to learn to organize and manage systems that find out and provide access to information kept elsewhere.

\section{E-Books:}

Locating relevant information in a timely manner is critical for both the researcher and the information professional. Electronic books (e-Books) are one way to enhance the digital library with global-24-hours-a-day and 7-day-a-week access to authoritative information, and they enable users to quickly retrieve access specific research material easily, quickly, and effectively. It is crucial to not only prove these electronic resources, but to integrate them into library streamline library operations, as well as promote user adoption. As an e-Book provider, net Library, a division of online Computer Library (OCLC), has been involved in the selection, cataloguing, and distribution of e-Books, Library, Library users are able to remotely search, locate, and checkout e-Books from the library's online public access catalogues (OPACs). As with any new opportunity new challenges emerge and utilizing the internet to deliver book content is no exception. Integrating e-Books into the digital library has created challenges and opportunities for librarians, publishers, and e-Books providers.

\section{E-journals (Electronic Journals):}

Electronic journal may be defined broadly as any journal, magazine, e-zone, newsletter or type of electronic serial publication which is available over the internet and can be accessed using different technologies such as World Wide Web, Gopher, ftp, 
telnet, e-mail or listserv. In some cases, print equivalents exist; in some cases, not. Some electronic journals are freely available; other charging mechanisms of different types.

Following are the worth mention advantage of the e-journals:

1. Speed of access to the latest information

2. Ability to implement multimedia elements

3. Quick searching

4. Linking from and to other resources

5. Security

6. Single user of location restrictions do not apply

7. Downloading an article to a personal computer for later use or printing is easier than photocopying or scanning.

\section{E-Mail:}

Electronic mail popularly known as 'E-Mail' is the most common service on the internet. It is a stone and forward service. It allows us to send messages many be a private latter, a request for software or a file and information on any subject and language from one machine to another. It does not require the presence of persons to receive e-mail because once the massage is addressed it is routed from one place to another until ultimately it appears at its destination. If the massage is addressed incorrectly or the network is unable for any reason to deliver it, the message will be bounced to senders email box.

E-mail address is made up of to parts, namely user names (the part before the @ sign) and a computer service name e.g. yahoo, Gmail, rediffmail, hotmail, unset, etc. 
finally the country code or the type of service provider. With reliable connectivity to internet one can use it to subscribe on-line magazines and newsletters, access to discussion groups, send and receive computer files and can use facilities such as fyp, gopher, WAIS, WWW etc. The basic E-mail functions are read, compose, reply, delete, include or attach, address book or alias, sorting of mail etc.

\section{Telnet:}

Telnet may be used by the College Libraries as an internet tool that allows a user to have an access to the front door of other networks, service or resources. It connects a workstation or node to a remote computer enabling a user to interact with it and issue commands to that computer. This facility allows one to have access to the data on the computer of another Colleges or institute. It facilitates to look at library catalogue, to see if a certain book has been published and to use one of the services of the information providers, such as Dialog. Most of the University Libraries USA and Europe viz. California University, Stanford University, Colorado University, Princeton University, Oxford and International organization like Library of Congress have made their library catalogue available for the internet user. Services like Gophers, line-mode web service and libraries can be had with the use of Telnet.

\section{Awareness and Use of New Trends for IT in Academic Libraries:}

The impact of new technologies is seen in almost every human activity. The size and the rate of growth and change in the pattern of collection, storage and transmission of information are some of the major limitations in any library. The basic concept in the use of new technology is technology is to free the information scientist, which can be entrusted to computer.

In this age of science, electronic computers provide information, which help to reduce the bulk of the printed materials. The computer also helps to make the libraries and society paperless in future. The developing countries like India have reached a stage, where technology particularly the communication technology threatens the very existence of traditional of traditional libraries. 
The convergence of electronics, computers and communications formed the basis for an advanced information society the main influence of information technology, that has a direct impact on information society, can be summed up as follows.

1. Increased computer power leading to faster and cheaper computer processing which facilitated automation of even low budget libraries.

2. Improved telecommunications, such as ISDN with greatly increased capacity for data transmission, which facilitated introduction of new services such as Electronic Mail, Fax, and Teleconferencing etc.

3. Cheaper data storage, such as optical storage media that increased the storage capacity of the libraries.

4. Digitization of information-Text, Graphics, Photographic speech; sound etc. that provides quick transmission of any type of data.

5. Better data transfer between different system and media, such as co-axial cables', optical fiber cables; satellite communication etc has promoted the resource sharing among the libraries.

6. Increased reliability of hardware and software, which has increased the performance efficiency.

7. User friendly systems that are developed to enhance the interface between technology and users of the library. (Zorkoczy) $)^{13}$

Consequent to the developments on information technology, the libraries are being provided with the means by which they can improve their services. The integrated library management is possible today with the application of information technology.

\section{Role and Present Status of IT in Academic Libraries:}

The role of computers in college libraries has more than one facet; one of them is that it is an object of 'information' in its own right as a service. Second could be as a tool for technology, the former role is vocational and the latter one is pedagogic. Apart from pedagogic use of computer can be used for knowledge generation and dissemination with the help of IT. 
The educational uses of the Internet can be classified into two major categories. The Internet, undertaking the goal of acquisition of skills and knowledge, sometimes represent content and at other times tools. In the course on the use of network technologies and services, and ways of using their potential, the Internet may be the content. This mode of use can be labeled 'Library Networking'.

In fact libraries and information centers has very important role in advancement of education, scientific research and socio-economic development of any society. These are the service centres, where very personalized service is extended to the users.

As a result of recent expansion in communication infrastructure, expanding computer culture, advances in printing technologies etc. has created more awareness about information use; it has resulted in increasing library services. The future libraries may not be recognized by verity of services and approaches, where information search areas will be outlined.

Most of the medical college libraries in Gujarat State are in much worse condition. Many college libraries are in a deplorable state without having even such basic amenities as shelves and technical personnel. There is need to improve the conditions in these libraries particularly in the context of explosion of knowledge and information in all disciplines. For the university libraries to become more efficient and accessible to as many scholars as possible and for this purpose automation has to introduce right away. This is essential to reduce the effort in collecting information, the time taken to locate it and resources spending.

The following few points briefly elucidate the various factors which have been affecting the change in library and information services.

1. In ancient times libraries were regarded as storehouse of knowledge and the services aspect was neglected largely. After the Second World War, dissemination of information has gained significance. The society has become more information conscious. To serve the information needs of diverse 
populations, different types of libraries, viz. public library, academic library and special library has emerged.

2. Political and economic factors play an important role in changing the scope of library and information services. The concept of globalization has opened the library and information services to wider community.

3. The innovation in information technology has brought changes in LIS Today it has become a common place for computer applications in information processing and retrieval. The technological innovations like networking, Internet, e-mail services, etc. have made information accessible to the user community worked over, promoting the concept of global village.

4. The limitation of finance, staff and equipments placed greater emphasis on adopting new management techniques by the library and information professionals. The change in management techniques requires specialized skills to be imparted to the information workers.

A survey was conducted by Medical College Libraries of Gujarat State to find how computers were used in libraries. As the most of the college libraries were not using computers is also insignificant. The reasons for this low use may be lack of technical support to the professional developing computer aided material and availability of relevant hardware and software. However, few of the college libraries serious efforts have been made to use of computer.

\section{Awareness and Use of IT in Academic Libraries Area:}

Very few of academic libraries are using IT for various library operations. The academic libraries can use IT for its various library services and operations such as acquisition, cataloguing, circulation, serials control and information services etc. for better utilizations of library resources for the maximum satisfaction of "Awareness and Use of Information Technology through a Theoretical and Constructive Observation of Academic Libraries”. Followings are some of areas where IT can be initiated successfully by the Academic Libraries Services. 


\section{Acquisition:}

The present study has been medical college libraries in computerized acquisition helps in selection, ordering, procuring books and other library materials. It helps in preparing subject- wise budget allocations. While selecting, ordering, accessioning books, libraries will be using most of the same bibliographical details of documents, such as, author, title, imprint, collection etc. In his process, computers enable libraries in making use of the same data available in different files without entering it again each time. In this way, computers help in performing the following important activities in acquisition.

1. Processing purchase requests

2. Pre-order searching

3. Approval process

4. Placement of orders

5. Receiving and accessioning documents

6. Invoice Processing and payment arrangement

7. Order follow-up and on-line enquires

8. Preparation of reports

\section{Cataloguing:}

Cataloguing is one the important functions which links the users requirement to the documents in the library. Computerized catalogue is the most efficient tool in retrieving information about the documents in a library easily and quickly. Catalogue of holdings can be prepared easily on the computer by importing the bibliographical details of the documents from acquisition file with additional data from library staff. Once the catalogue of holdings is available on the computer, the documents can be searched, retrieved and rearranged in any way as desired. The time consuming work involved in the following activities is significantly reduced by using computers.

1. Catalogue cards production

2. Catalogue maintenance 
3. Thesaurus construction

4. Indexes- authors, keywords, etc.

5. OPAC

\section{Serial Control:}

Computers help in periodicals subscription and subsequent monitoring of the receipts of individual issues. In computerized serials management, it will be easier to detect and contrail the no-receipts of the periodicals issues by sending timely remainders to suppliers. It helps in maintaining record of budget sanctioned and amount expended for different categories of serials. Computerized serials control helps in creating a database of journals with all the details.

1. Processing new subscriptions

2. Processing renewal subscriptions

3. Order placing and invoice processing

4. Receiving and recording issues

5. Claiming missing issues

6. Bindery management

7. Maintenance of list of periodicals

8. Serials Holdings

\section{Circulation:}

Circulation of documents is one of the important operations of a library. Circulation procedure in a conventional system is very lengthy and a user much of the staff times in repetitive works. The use it technological devices such as computers, barcode scanners and its software in circulation helps in performing these routine operations easily and quickly, it saves lot of time for the staff as well as users. It helps in maintaining up-to-data membership records and in finding out latest status of documents under circulation. IT helps in the following activities in circulation.

1. Issue and Return of Documents

2. Renewal and Reservation of Documents 
3. Sending Reminder Notice

4. Circulation and Collection of Overdue

5. Maintenance of Membership Records

6. Circulation Statistic

7. Stock Verifications

\section{Management Support:}

Library management needs information for taking right decisions. Information facilitates decision-making. Computerized library can provide information quickly on various library activities required by the management for the following purposes.

1. Budgetary Control

2. Preparation of Accounts

3. Maintenance of Records

4. Library Statistics

5. Generation of Reports

\section{Information Services:}

Libraries are experiencing a significant import of IT on information processing, source and services developments in IT made information sources available in different formats such as floppies, CD-ROMs, Network, Databases, and Multimedia etc. Libraries have to make efforts to facilitate users access to these information sources. IT has brought a revolutionary change in faster information communication across the globe resulting in a number of new information services. Use of information technology in library results in cost efficient and cost-effective information services. The following are some the important information services.

1. Reference Services

2. Information Search Services

3. Bibliography and Indexing Services

4. Inter-library loan Services

5. Current Awareness Services (CAS) 
6. Selective Dissemination of Information (SDI)

7. Document delivery Services

\section{Conclusion:}

Information Technology (IT) will play a vital role in the $21^{\text {st }}$ century. There is a sure indication that the conventional present study based documents would vanish from everyday life. The information revolution of today is indisputable caused by the unprecedented advances in information technology. Comprising computers, telecommunications, micrographics and reprographics. All these are pointers towards a paperless society. In a nutshell, libraries would continue to render and to procure cost effective information sources.

Information technology is the boon for mankind. It gives accessibility to information at fingertips. There has been discussion on 'Information Highways' and high tech libraries. The promising and diversified possibilities of information technology have reduced the space and time between the people, country, and continent and ultimately have led to the emerging concepts 'Global Society' and 'Global Village'.

\section{References:}

1. Bhatt, Atul, "An Analytical study of the Medical College Libraries of Gujarat in the Age of Information Technology" (2012). Library Philosophy and Practice (e-journal). Paper 697.

2. Bhatt, Atul Ashokbhai (2014),"Information needs, perceptions and quests of law faculty in the digital era", The Electronic Library, Vol. 32 Iss 5 pp. 659 - 669 http://dx.doi.org/10.1108/EL-11-2012-0152

3. Enser, P.G.B., (1988) Information Technology and the Librarian, Library science with slant to documentation, Vol. 25(1), March, P.1.

4. Katherine, Martine (1994) Understanding the forces for and against electronic information, CD-ROM Professional Vol. 7 No. 4 (July/ August) P. 129-134.

5. Kumbar, Mallinath (1995) Use of information technology in library services, Herald of Library Science, Vol. 35 (1-2), P. 20-21. 
6. Lancaster, F. W. (1978) Towards Paperless Information System, New York, Academic, P. 5-8.

7. Patil, D. B. and Kooganurmath, M. M. eds (1954) Library and Information Science, New Delhi: Ashish, P. 5.

8. Patil, D. B. and Kooganurmath, M. M. eds (1954) Library and Information Science, New Delhi: Ashish, P. 6.

9. Rayudh, C. S. (1993) Media and Communication Management, Bombay, Himalaya Prakashan, P. 466.

10. Resnikoff, R. L. (1980) The social significance of information science, communication year book, P. 115-120.

11. Sathaynarayana, R. (1996) Information Technology and its facets, New Delhi; Mank, P. 67.

12. Soonchul, Lee and Michel, E. Treachy (1988) 'Information Technology impact on innovation' R \& D Management Vol. 18 No. 3, October, P.257-271.

13. Taneja, S. R. (1997) Changing Trends in LIS, DESIDOC, Bulletin of information technology, Vol. 17 (3), P. 21.

14. Zorkoczy, Peter (1989) Information Technology: An Introduction, $2^{\text {nd }}$ ed. New Delhi; Affiliated East-West, P.6.

15. Zorkoczy, Peter (1989) Information Technology: An Introduction, $2^{\text {nd }}$ ed. New Delhi; Affiliated East-West, Op cit. (8), P.3.

\author{
Dr. Rajeshkumar M.Gamit \\ Assistant Professor \\ Department of Library and Information Science \\ Gujarat University, Ahmedabad-380009 \\ Email: rajeshkumargamit@gmail.com
}

